\title{
Toxicity to Bivalve Hemocytes of Pathogenic Vibrio Cytoplasmic Extract
}

\author{
Christophe Lambert ${ }^{\mathrm{a}}$, Jean-Louis Nicolas ${ }^{\mathrm{a}},{ }^{*}$ and Valérie Bultel ${ }^{\mathrm{b}}$
}

a : Laboratoire de Physiologie des Invertébrés Marins, Direction des Ressources Vivantes, Centre de Brest, IFREMER, B.P. 70, 29280, Plouzané, France

b : Laboratoire de Chimie des Substances Naturelles, MNHN, 63 rue Buffon, 75231, Paris cedex 05 , France'

*: Corresponding author : Fax.: +33 2982247 57, E-mail: jlnicola@ifremer.fr

\begin{abstract}
:
Using a chemiluminescence (CL) test, it had been previously demonstrated that Vibrio pectenicida, which is pathogenic to Pecten maximus larvae, was able to inhibit completely the CL activity of $P$. maximus hemocytes and partially inhibit those of Crassostrea gigas. Conversely, a Vibrio sp. strain, S322, pathogenic to $C$. gigas larvae was more active in reducing the CL activity of oyster hemocytes than of scallop hemocytes. Using this same CL biotest, $V$. pectenicida and S322 cytoplasmic extracts were shown to reproduce CL inhibition while the cytoplasmic extract of a nonpathogenic strain (U1, Pseudoalteromonas) was without effect. Moreover, cytoplasmic extract as well as live $V$. pectenicida cells provoked, within a few hours, death of $P$. maximus hemocytes adhering to a glass slide. After partial purification, it was shown that toxic activities of $V$. pectenicida cytoplasmic extract was due to a toxin, named VHKT (for vibrio hemocyte-killer toxin), which is heat stable, acid and protease resistant, and less than $3 \mathrm{kDa}$ in molecular weight. Attempts to purify VHKT by reverse-phase (C18) HPLC separated activity into the fraction eluted by water at a retention time of $4.02 \mathrm{~min}$.
\end{abstract}

Keywords: Toxicity to bivalve hemocytes of Vibrio extract. 


\section{Introduction}

Previously, Lambert and Nicolas (1998) demonstrated specific inhibition of the chemiluminescence (CL) activity of bivalve hemocytes by pathogenic vibrios. Vibrio pectenicida (strain A496 ) virulent to Pecten maximus larvae (Nicolas et al., 1996; Lambert et al., 1998) suppressed completely the CL activity of scallop hemocytes but only partially suppressed the activity of Crassostrea gigas hemocytes. With another Vibrio sp. (S322), pathogenic to oysters, the opposite results were obtained. The hypothesis proposed to explain this specificity was either that is was due to specific attachment by pili or flagella to the hemocyte membrane, or possibly due to different toxins.

Toxins of vibrios involved in human disease, including $V$. cholerae, $V$. vulnificus and $V$. parahaemolyticus, have been studied extensively. Some toxins from vibrios which are virulent to fish, such as $V$. anguillarum, have also been characterised. For bivalve larvae and other molluscs, few results have been reported. The activity of toxins was demonstrated by exposure of larvae to diluted bacterial culture supernatants (Umbreit and Tripp, 1975; Brown and Roland, 1984). Nottage and Birkbeck (1986) purified a ciliostatic toxin from $V$. alginolyticus with a low molecular weight. In case of V. pectenicida (Lambert, 1998), inoculation of cytoplasmic extract to axenic culture of $P$. maximus larvae caused as high mortality as live bacteria.

In the present work, using the CL test described by Lambert and Nicolas (1998), we attempted to demonstrate the presence of a toxic molecule in the bacterial cytoplasm of $V$. pectenicida and Vibrio sp. strain S322 and to further purify and characterise the $V$. pectenicida toxin. 


\section{Materials and methods}

\section{Bivalves}

Thirty adult scallops and oysters, three or four-year old, were collected in the Bay of Brest (Brittany). Scallops were maintained at $15{ }^{\circ} \mathrm{C}$ in a $450 \mathrm{~L}$ sea-water tank equipped with a sand filter and air-lift system. They were fed just close to satiation on a four micro-algae mixture which included Isochrysis affinis galbana (1 to 2.6 x $10^{9}$ cells/day/animal), Pavlova lutheri (1 to $2.6 \times 10^{9}$ cells/day/animal), Chaetoceros calcitrans (0.5 to $1.3 \times 10^{9}$ cells/day/animal), and Skeletonema costatum (0.3 to $0.5 \times 10^{9}$ cells/day/animal).

For Crassostrea gigas, the same conditions were applied, except for the temperature $\left(18^{\circ} \mathrm{C}\right)$ and the diet (1,1 to 2,9.109 cells/day/animal).

They were maintained, for at least two weeks, in constant conditions of temperature and feeding before sampling.

\section{Inoculated Bacteria}

Three strains were used: strain A496 of V. pectenicida (CIP 105229), strain S322, pathogenic to oyster larvae (C. gigas) and strain U1, collected from the dominant flora of $P$. maximus larval cultures. The affiliation of both $\mathrm{U} 1$ and S322 was obtained by sequencing the $16 \mathrm{~S}$ rDNA and by phylogenetic analysis. Strain S322 was close to V. orientalis whereas U1 was located inside the Pseudoalteromonas genus.

Before inoculation, the three strains were cultured in Marine broth (Difco) at $18{ }^{\circ} \mathrm{C}$, without shaking, for 48 hours which corresponded to the end of the exponential phase. The bacterial cells were collected by centrifugation $(5,000 \mathrm{~g}, 10 \mathrm{~min})$, washed twice in sterile sea-water (SSW) and re-suspended in SSW. Concentration was checked by measurement of optical density (O.D.) at $540 \mathrm{~nm}$ for which the correlation between direct counts and O.D. had previously been established (Lambert, 1998). 


\section{Bacterial extracts}

Extracts were obtained from the three bacterial cultures.

Strain A496 was cultured first in Marine Broth 2216E (Difco) in a $250 \mathrm{~mL}$ conical flask. After 48h growth, the culture was transferred to a $15 \mathrm{~L}$ fermentor using growth conditions of $25^{\circ} \mathrm{C}, \mathrm{pH} 7.8$ and $100 \%$ oxygen saturation. Bacterial concentration was checked by regular measurement of O.D. $540 \mathrm{~nm}$. The stationary phase was reached after 26h, when 41 grams of bacterial cells, about $1.5 \times 10^{13}$ cells, were collected using continuous centrifugation. Cells were suspended in $100 \mathrm{~mL}$ of sterile $1 \%(\mathrm{w} / \mathrm{v}) \mathrm{NaCl}$ and then disrupted by a double high pressure treatment $\left(18,000\right.$ psi) in a French Press ${ }^{\circledR}$ system. The bacterial suspension was then centrifuged $(100,000 \mathrm{~g}, 40 \mathrm{~min})$ to separate membrane and cytoplasmic fraction. The supernatant (cytoplasmic extract) was carefully removed, $0.2 \mu \mathrm{m}$ filtered (Minisart SRP 25 filter, Sartorius), divided into $1.6 \mathrm{~mL}$ volumes in Eppendorf tubes and frozen at $-80^{\circ} \mathrm{C}$.

The same protocol was used for strains U1 and S322, but, they were cultured only in $200 \mathrm{~mL}$ flasks. About $2.3 \times 10^{11}$ cells for U1 and $7.2 \times 10^{10}$ cells for S322 were collected from the cultures.

The yield of the French Press ${ }^{\circledR}$ system was evaluated by protein measurement (Lowry method: Waterborg and Matthews, 1984) before and after treatment. The result was in agreement (72\%) with those (75 to $100 \%$ given by Hancock and Poxton (1988). Taking account of these assays, $1 \mu \mathrm{L}$ of cytoplasmic extract corresponded to $1.1 \times 10^{8}$ cells for A496, $0.25 \times 10^{8}$ cells for S322 and $0.32 \times 10^{8}$ for $\mathrm{U} 1$.

\section{CL assays}

Hemolymph collection in scallop and oyster was as described previously by Lambert and Nicolas (1998). 
The protocol for CL assays was first described by Bachère et al. (1991) and adapted by Lambert and Nicolas (1998). Briefly, the hemolymph, diluted with modified anti-aggregant Alsever solution (MAS, Bachère et al., 1988), was distributed into plastic scintillation vials at $1 \times 10^{5}$ hemocytes per vial. This solution was made up to $2 \mathrm{~mL}$ with luminol solution (200 $\mu L)$ and SSW.

Generation of chemiluminescence was measured with a liquid scintillation counter set to measure repeated sequential counts. Results were expressed in counts per minute (cpm). At the end of the experiment, the CL activity levels in control hemocyte samples after stimulation with zymosan particles, 80 particles per hemocyte (the optimal concentration previously determined by Bachère et al., 1991) were compared to the CL activity levels of hemocytes previously in contact for 80 min with bacteria or bacterial extract. Each set of hemocytes was made up of four replicates, i.e. four vials. In each experiment, one set of 4 vials without hemocytes was also used to determine the "zero level" and one set, with hemocytes but not stimulated by zymosan and not exposed to bacteria or bacterial extracts, was used to determine the "base level".

Significant differences between CL responses of treated groups were determined at the peak of CL activity due to zymosan stimulation using variance analysis $(n=4, \alpha=0.05)$.

Five CL assays were carried out to determine the effect of A496, S322 and U1 cytoplasmic extracts and then six CL assays to identify the features of the toxic molecule.

\section{CL assays using cytoplasmic extracts of A496, U1 and S322}

A first CL experiment was performed using live cells of A496 and A496 cytoplasmic extracts. In addition to control, zero and base sets of hemocytes, one set of four vials of P. maximus hemocytes was inoculated with 100 cells of $V$. pectenicida (strain A496) per hemocyte, the 
optimal ratio previously determined by Lambert and Nicolas (1998), and 4 sets respectively inoculated with $0.8,4,8$ and $16 \mu \mathrm{L}$ of A496 bacterial extract.

A second experiment was performed to compare the activity of $25 \mu \mathrm{L}$ of A496 cytoplasmic extract to $83 \mu \mathrm{L}$ of $\mathrm{U} 1$ cytoplasmic extract, which corresponded to the same quantity of bacterial cells (about $2.4 \times 10^{9}$ ) as $25 \mu \mathrm{L}$ of A496 extract.

A third CL experiment was done to study the toxic effect of S322 bacterial extract on oyster hemocytes. The same protocol as for A496 strain was used except that the 4 other sets were exposed to 2, 20, 66 and $200 \mu \mathrm{L}$ of S322 cytoplasmic extract respectively.

To compare the level of activity of A496 and S322 extracts, two CL assays were performed with both types of hemocytes (oyster and scallop). In each vial, 100,000 hemocytes were distributed, and then $16 \mu \mathrm{L}$ of A496 extract were inoculated, i.e. 2.0 x $10^{9}$ equivalent bacteria. To obtain the same level of « equivalent bacteria », $800 \mu \mathrm{L}$ of S322 extract was used. This extract was concentrated to $50 \mu \mathrm{L}$ by vacuum evaporation before inoculation. A CL assay using evaporated extract (vacuum, $80^{\circ} \mathrm{C}$ ) had previously shown no loss of activity.

\section{Features of the toxic molecule}

For the next 8 CL assays, in addition to control, zero and base sets, one set of hemocytes was inoculated with $25 \mu \mathrm{L}$ of A496 cytoplasmic extract and one set with the same inoculum after different chemical or physical treatments (see below). To evaluate the effect of the treatment, a control set of hemocytes was inoculated with sterile $1 \%(\mathrm{w} / \mathrm{v}) \mathrm{NaCl}$ after the same treatment (= control treatment).

Treatments were: 
- cytoplasmic extract heated for $10 \mathrm{~min}$ at $70^{\circ} \mathrm{C}$, or $10 \mathrm{~min}$ at $100{ }^{\circ} \mathrm{C}$. Precipitated proteins were discarded after centrifugation (10,000 g, $10 \mathrm{~min})$.

- cytoplasmic extract incubated for 1 hour at $35^{\circ} \mathrm{C}$ with a final concentration of $0.4 \mathrm{mg} \cdot \mathrm{mL}^{-1}$ proteinase $\mathrm{K}$ (Sigma). Proteinase $\mathrm{K}$ was then inhibited by addition of $1 \mathrm{mM}$ (final concentration) PMSF (phenylmethanesulfonyl fluoride, Sigma).

- Protein precipitation with perchloric acid: $1.6 \mathrm{~mL}$ of A496 cytoplasmic extract was diluted by addition of $5.07 \mathrm{~mL}$ of $1 \%(\mathrm{w} / \mathrm{v}) \mathrm{NaCl}$. After $\mathrm{pH}$ measurement, $0.51 \mathrm{~mL}$ of perchloric acid $\left(\mathrm{HClO}_{4}, 70 \%, 0.9 \mathrm{M}\right.$ final concentration) was added. The protein deposit was discarded after centrifugation (10,000 g, $10 \mathrm{~min})$, and the supernatant neutralised by adding about $1.3 \mathrm{~mL}$ of $2.5 \mathrm{M}, \mathrm{K}_{2} \mathrm{CO}_{3}$.

- Protein precipitation with trichloracetic acid (TCA): $1 \mathrm{~mL}$ of $15 \%(\mathrm{w} / \mathrm{v})$ trichloracetic acid solution was added to $1 \mathrm{~mL}$ of A496 cytoplasmic extract. After centrifugation (10,000 g, $10 \mathrm{~min}$ ), the $\mathrm{pH}$ of the supernatant was neutralised by adding about $3 \mathrm{~mL}$ of the following mixture: Freon (1.1.2 trichlorotrifluoroethane 99\%) $2.5 \mathrm{~mL}$, amine (tri-noctylamine) $0.5 \mathrm{~mL}$. The amine-Freon method allowed neutralisation of the $\mathrm{pH}$ of the supernatant in a constant volume.

\section{Lipid extraction:}

- using butanol : $1 \mathrm{~mL}$ of extract was mixed with $1 \mathrm{~mL}$ of butanol. After vigorous shaking and centrifugation for $5 \mathrm{~min}$ at 9,000g, the upper phase containing butanol and lipids was collected. A second extraction was performed under the same conditions and the 2 phases were again separated. Butanol from the lipid phase was evaporated and lipids were dissolved in $1 \mathrm{~mL}$ of $1 \% \mathrm{NaCl}, 0.1 \%$ DMSO (dimethyl sulfoxide) solution. Two « controls treatments » corresponding to each phase were made using the same conditions. 
- using the method of Bligh and Dyer (1959): one mL of cytoplasmic extract was mixed with $2 \mathrm{~mL}$ ethanol and $1 \mathrm{~mL}$ chloroform. After shaking, the mixture was homogenous. On adding $1 \mathrm{~mL}$ of ice-cold water and $1 \mathrm{~mL}$ of chloroform, and shaking, chloroform containing lipids was separated. Both phases were collected, evaporated and redissolved in $10 \% \mathrm{NaCl}$ (with 0.1\% DMSO for lipid phase). For each phase, one « control treatment » was performed.

Separation by ultrafiltration

The A496 cytoplasmic extract, previously treated with trichloracetic acid to eliminate large macromolecules, was filtered by centrifugation (3,000 to 5,000 g) using Microsep ${ }^{\mathrm{TM}}$ Filtron tubes calibrated at 30, 10, 3 and $1 \mathrm{kDa}$ molecular weight cut-off.

\section{HPLC chromatography}

Two assays were performed:

1) $200 \mu \mathrm{L}$ of A496 cytoplasmic extract, previously treated with TCA and $1 \mathrm{kDa}$ filtered, was separated by HPLC on a reverse-phase C-18 column (Hypersil, $250 \mathrm{~mm}$ length), which was eluted with a methanol gradient from 5 to 50\%, 1 mL. min $^{-1}$ (Pump: L-6200A Merck-Hitachi), and with a $206 \mathrm{~nm}$ detector (L-4250C UV- Vis Merck detector); a total of 14 fractions were collected at 2 min intervals using a Gilson FL203B fraction collector. From the elution profile, fractions 1, 2 and 3 were combined. Activities of the 12 fractions, previously vacuum evaporated $\left(80^{\circ} \mathrm{C}\right)$, were tested using the CL assays.

2) $100 \mu \mathrm{L}$ of A496 cytoplasmic extract, previously treated with TCA and $1 \mathrm{kDa}$ filtered, was separated by HPLC on a reverse-phase C-18 column (Chromasil, $250 \mathrm{~mm}$ length), eluted with water, $2 \mathrm{~mL}$. $\min ^{-1}$ (Pump: L-6200A Merck-Hitachi), and absorbent material detected at 230 
nm (L-4250C UV- Vis Merck detector). Nine fractions were collected and activity of the fractions, previously vacuum evaporated $\left(80^{\circ} \mathrm{C}\right)$, was then tested using CL assays.

\section{Cytotoxic effect}

To demonstrate the toxic activity of A496 strain and A496 cytoplasmic extract on the viability of the hemocytes of $P$. maximus, 100,000 hemocytes were withdrawn from two scallops and dispersed onto a glass slide in $80 \mu \mathrm{L}$ SSW. Experiment was done in triplicate. A first set of slides was used as a control. In the second set, 100 bacterial cells per hemocyte (A496 strain) were added. In the third set, $25 \mu \mathrm{L}$ of the A496 cytoplasmic extract were used. After 6 hours incubation in a wet chamber at $20{ }^{\circ} \mathrm{C}$, the viability of hemocytes was checked using the acridine orange / ethidium bromide method (Mishell and Shiigi, 1980).

Counting of viable cells was made on 200 cells per slides and the comparison of means was made using variance analysis $(n=3, \alpha=0.05)$. 


\section{Results}

\section{Activity of $V$. pectenicida (A496 strain) cytoplasmic extract}

Results presented in Fig.1 show the capacity of A496 bacterial extract to inhibit the CL activity of $P$. maximus hemocytes stimulated by zymosan particles. The inhibition was directly linked to the dose of bacterial extract. For 0.8 and $4 \mu \mathrm{L}$ there was no significant inhibition compared to the control. For $8 \mu \mathrm{L}$, the inhibition was significant (ANOVA $n=4, \alpha$ $=0.05$ ), and a $16 \mu \mathrm{L}$ dose provoked an effect equivalent to that induced by live A496 bacteria.

These results showed clearly that the cytoplasmic extract of the strain A496 had the same dose-dependent capacity as live bacteria in inhibiting the CL activity of $P$. maximus hemocytes.

\section{Activity of U1 cytoplasmic extract}

Results presented in Fig. 2 show a significant difference (ANOVA $n=4, \alpha=0.05$ ) after stimulation by zymosan between CL activity level of hemocytes either previously in contact with U1 extract or A496 extract. Previous contact with U1 cytoplasmic extract did not affect the CL activity of hemocytes and the CL level reached was not significantly different from that of the control. At the same time, there was a strong inhibition of the hemocyte CL activity after contact with A496 extract (> 50\%). This result confirmed the toxic capacity of $V$. pectenicida (strain A496) cytoplasmic extract against the CL activity of $P$. maximus hemocytes.

\section{Activity of S322 cytoplasmic extract on oyster hemocytes}

Results presented in Fig. 3 show the capacity of S322 bacterial extract to inhibit the CL activity of C. gigas hemocytes stimulated by zymosan particles. The inhibition was directly 
linked to the dose of bacterial extract. For $2 \mu \mathrm{L}$ there was no significant inhibition compared to the control. For 20, 66 and $200 \mu \mathrm{L}$, the inhibition was significant (ANOVA $n=4, \alpha=$ $0.05)$.

These results showed that the cytoplasmic extract of the strain S322 had the same dosedependent capacity as live bacteria to inhibit the CL activity of C. gigas hemocytes. As shown with $V$. pectenicida, these results confirmed the presence of a toxic molecule in the cytoplasm of this pathogenic vibrio.

\section{A496 and S322 cytoplasmic extratct activity : loss of specificity}

As shown in Table 1, there was no significant difference between CL activity reached by both scallop and oyster hemocytes after zymosan stimulation, in the case of prior contact with S322 or A496 cytoplasmic extracts. Therefore, it seemed that live A496 and S322 cells were able to inhibit specifically the CL activity of the hemocytes of their usual host ( $P$. maximus for A496 and C. gigas for S322), but this specificity of action disappeared when using cytoplasmic extracts. The fact that there was strong inhibition in all cases strongly confirmed the presence of a toxic molecule.

\section{Characterisation of the toxic molecule}

The results of the 8 CL assays performed to define some basic features of the toxic molecule from the A496 cytoplasmic extract showed that, in all cases, the CL activity of hemocytes in the «control treatment » did not show any significant difference compared with the nontreated hemocytes, i.e., there was no interference between the different treatments on toxic activity. for fractions which led to a significant decrease of the CL activity of $P$. maximus hemocytes (ANOVA $n=4, \alpha=0.05$ ), there was no decline in toxic activity if the A496 cytoplasmic extract has been previously heated to $70{ }^{\circ} \mathrm{C}$ or $100{ }^{\circ} \mathrm{C}$, treated with proteinase $\mathrm{K}$, 
perchloric or trichloracetic acid. The main toxic activity was found in the non-lipid fraction of the cytoplasmic extract using butanol extraction, but the activity was present both in lipid and non-lipid fraction using the Bligh and Dyer method.

After ultrafiltration, it was not possible to differentiate statistically (ANOVA, $n=4, \alpha=0.05$ ) the inhibition of hemocytes CL activity depending on whether they were previously in contact with A496 cytoplasmic extracts filtered at 30, 10, 3 or $1 \mathrm{kDa}$ and the unfiltered control.

These results showed that the toxic activity was probably due to a small molecule $(<3 \mathrm{kDa})$, which was heat resistant, acid and protease resistant and water soluble. Results after lipid extraction could suggest that there was more than one molecule, or a complex one, which was partly lipid. Nevertheless, there was strong activity in the water fraction.

\section{Purification assays}

Using HPLC with a C18 reverse phase column to separate the A496 cytoplasmic extract which had been previously TCA treated and $1 \mathrm{kDa}$ filtered, it appeared (Figure 4) that in case of elution with a methanol gradient from 5 to $50 \%$, the toxic activity was eluted in the first peak, corresponding to fractions $1+2+3$. Using water as the elution solution (Figure 5), the main toxic activity appeared in fraction 5, with a retention time $4.02 \mathrm{~min}$. These results confirmed that the toxic molecule was in the water fraction of the extract.

\section{Cytotoxic effect on hemocytes : glass slides experiment}

After 6 hours, the mean percentage of viable hemocytes in control slides was $76.1 \%$, but only $30.5 \%$ in case of hemocytes in contact with A496 bacterial cells, and $7.2 \%$ in case of hemocytes in contact with A496 cytoplasmic extract (significant difference versus control, n 
$=3, \alpha=0.05$ ). In the last two cases (bacterial cells and cytoplasmic extract) hemocytes were rounded without typical pseudopodia and filopodia.

\section{Discussion}

In the present work, contact of hemocytes with the cytoplasmic extract of $V$. pectenicida (strain A496) and Vibrio sp. (strain S322) provoked the same CL inhibition as bacterial cells, whereas the cytoplasmic extract of U1 strain (non pathogenic), tested under the same conditions, was unable to inhibit the CL activity. A dose response effect was also observed in both vibrio extracts.

It is not easy to correlate bacterial pathogenic activity with toxic activity. For instance, Egidius (1987) emphasised the difficulties of some authors in relating haemolytic capacity of $V$. anguillarum with its pathogenic activity. However, in case of $V$. pectenicida, the ability to induce mortality in P. maximus larvae seems partly due to its capacity to kill hemocytes. Toxic molecules in the bacterial cytoplasm reproduced the inhibition of CL activity and accelerated hemocyte death. $V$. pectenicida was also probably able to interfere with other phagocytic cells of the digestive gland. In this way, through its internal toxins, $V$. pectenicida may disrupt the defence system of the larvae and the digestive system too.

However, to produce a similar CL inhibition activity to 100 live bacterial cells per hemocytes (1 x $10^{7}$ bacterial cells per vial) using cytoplasmic extract, required about $2.4 \times 10^{9}$ bacteriaequivalents per vial, e.g. about 276 times more. This phenomenon can be explained by the fact than only part of the toxic factors were present in the cytoplasmic extract; either active molecules were in the form of less active or inactive precursor, or they were bound to the membrane and only partially released by the French press procedure. The chemical and physical treatments applied to obtain the extract could also explain part of the loss of activity. Moreover, if whole bacteria were actively phagocytosed leading to higher cytoplasmic concentration of toxicant, there was no similar active phagocytosis using free toxins. 
Another question is the mode of action of this toxin. In a first attempt, two main hypotheses can be suggested: either the toxin acts specifically on one or another step of the metabolic respiratory burst $(\mathrm{RB})$ pathway, or its cytotoxic activity is sufficiently strong to lead quickly to hemocyte death. This last hypothesis seems the more probable. In fact, the experiments on glass slides showed the capacity of vibrio extracts to lead to hemocytes death within 6 hours, although it is likely that it occurred earlier. Be that as it may, the present work allowed some features of the toxic molecule of $V$. pectenicida to be determined. One of the active factors, that we named VHKT, for Vibrio Hemocyte-Killer Toxin, was heat stable, protease and acid resistant and water soluble. It was also a small molecule, less than $3 \mathrm{kDa}$, and all these features make it unlikely that VHKT is a protein. Using HPLC, the active fraction of the $V$. pectenicida extract was present in the fraction eluted with water. Unfortunately, RMN analysis on the active fraction ( $\mathrm{n}^{\circ}$, reverse phase C18 chromasyl, retention time $4.02 \mathrm{~min}$ ) showed a complex composition, necessitating further other purification steps.

However, from available data, it was interesting to compare VHKT to some other toxins from vibrios. Sears and Kapers (1996) reviewed the toxins from V. cholerae, V. fluvialis, V. hollisae, $V$. parahaemolyticus, $V$. mimicus and $V$. metschnikovii but the activities or properties of these toxins were not comparable to those of VHKT. By focusing on vibrios species pathogenic for marine animals, the ciliostatic toxin described by Nottage et al. (1989) was close to VHKT in terms of thermo-resistance and low-molecular weight ( $<5 \mathrm{kDa})$. But, tests made using the method described by Nottage et al. (1989) to demonstrate ciliostatic activity showed that $V$. pectenicida, either live bacteria or cytoplasmic extracts were not effective in reducing the ciliary activity of Mytilus edulis gills (Data not shown). So, it is likely that VHKT is a new toxin but further characterisation of the molecule is required. 
Acknowledgements. We thank Jean-René Le Coz (Laboratoire de Physiologie des Invertébrés Marins, IFREMER, Brest, France) who performed part of the HPLC analyses. 


\section{References}

Bachère, E., Chagot, D., and Grizel, H. 1988. Separation of Crassostrea gigas hemocytes by density gradient centrifugation and counterflow centrifugal elutriation. Dev. Comp. Immunol. 12, 549-559.

Bachère, E., Hervio, D., and Mialhe, E. 1991. Luminol-dependent chemiluminescence by hemocytes of two marine bivalves, Ostrea edulis and Crassostrea gigas. Dis. Aquat. Org. 11, 173-180.

Bligh, E.G., and Dyer, J. 1959. A rapid method of total lipid extraction and purification. Can. J. Biochem. Physiol. 37, 911-917.

Brown, C., and Roland, G. 1984. Characterization of exotoxin produced by a shellfishpathogenic Vibrio sp. J. Fish Dis. 7, 117-126.

Egidius, E., 1987. Vibriosis: Pathogenicity and pathology. A review. Aquaculture 6, 15-28.

Hancock, I.C., and Poxton, I.R. 1988. Bacterial cell surface technique. In "Modern Microbiological Methods”, p. 56. A Wiley-Interscience publication. John Wiley \& sons Ltd.

Lambert, C. 1998. Etude des infections à Vibrionaceae ches les larves de mollusques bivalves à partir d'un modèle larve de Pecten maximus. Thesis doctoral, Université de Bretagne Occidentale, Brest (France), 182 pp.

Lambert, C., and Nicolas, J.L. 1998. Specific inhibition of chemiluminescent activity by pathogenic vibrios in hemocytes of two marine bivalves: Pecten maximus and Crassostrea gigas. J. Invertebr. Pathol. 71, 53-63.

Lambert, C., Nicolas, J.L., Cilia, V., and Corre, S. 1998. Vibrio pectenicida sp. nov. a pathogen of scallop (Pecten maximus) larvae. Int. J. Syst. Bacteriol. 48, 481-487. 
Mishell, B.B., and Shiigi, S.M. 1980. In « Selected methods in cellular immunology », pp. 2122. Edited by Mishell, B.B. and S.M. Shiigi, W.H. Freeman and company, San Fransisco.

Nicolas, J.L., Corre, S., Gauthier, G., Robert, R., and Ansquer, D. 1996. Bacterial problems associated with scallop (Pecten maximus) larval culture. Dis. Aquat. Org. 27, 67-76.

Nottage, A.S., and Birkbeck, T.H. 1986. Toxicity to marine bivalves of culture supernatant fluids of the bivalve-pathogenic Vibrio strain NCMB 1338 and other marine vibrios. J. Fish Dis. 9, 249-256.

Nottage, A.S., Sinclair, P.D., and Birkbeck, T.H. 1989. Role of low-molecular-weight ciliostatic toxins in vibriosis of bivalve mollusks. J. Aquat. Anim. Health 1, 180-186.

Sears, C.L., and Kaper, J.B. 1996. Enteric bacterial toxins: mechanisms of action and linkage to intestinal secretion. Microbiol. Rev. 60, 167-215.

Umbreit, T.H., and Tripp, M.R. 1975. Characterization of the factors responsible for death of fish injected with Vibrio anguillarum. Can. J. Microbiol. 21, 1271-1274.

Waterborg, J.H., and Matthews, H.R. 1984. The Lowry method for protein quantification. In "Methods in molecular biology", Volume 1 "Proteins”, pp. 1-3. Edited by John M. Walker; Humana Press, Clifton, New Jersey. 


\section{TABLE}

Table 1: Comparison of the CL activity Level (cpm: mean, $n=4)$ of hemocytes (Pecten maximus and Crassostrea gigas) stimulated with zymosan particles, according to the type of cytoplasmic extract (Vibrio sp. strain S322 or Vibrio pectenicida strain A496) previously in contact with them.
Pecten maximus hemocytes
Crassostrea gigas hemocytes
(CL activity in cpm)
(CL activity in cpm)

\begin{tabular}{ccc}
\hline A496 extract & $4.16 \times 10^{4}(\mathrm{~ns})$ & $0.50 \times 10^{6}(\mathrm{~ns})$ \\
S322 extract & $5.12 \times 10^{4}(\mathrm{~ns})$ & $1.31 \times 10^{6}(\mathrm{~ns})$ \\
control & $9.93 \times 10^{5}(*)$ & $1.20 \times 10^{7}(*)$ \\
\hline
\end{tabular}

(ns): no significant difference between A496 and S322 extract; $\left(^{*}\right)$ : significant difference between control and extracts. (ANOVA, $\mathrm{n}=4$, alpha $=0.05$ ). 


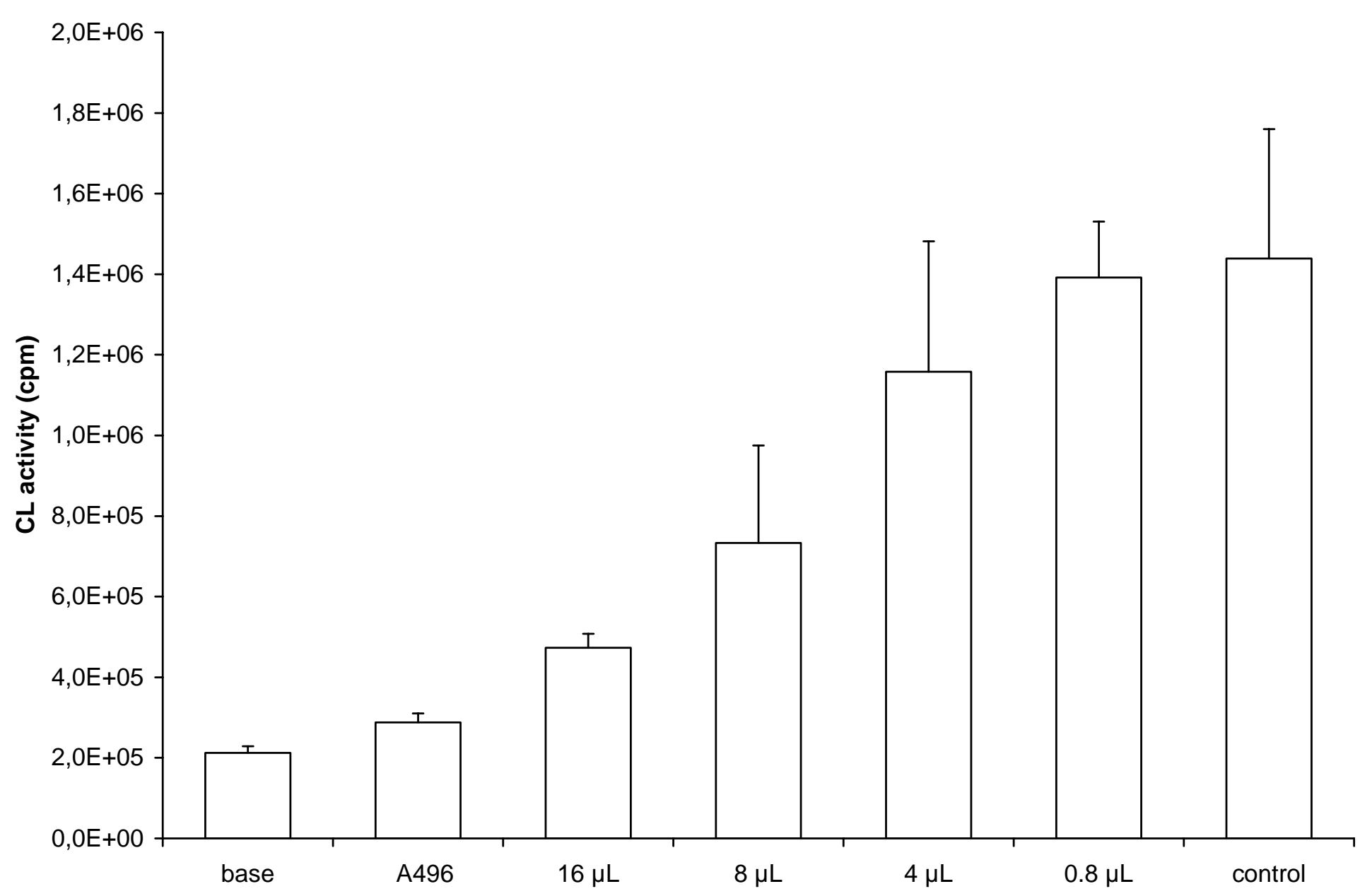

FIG. 1: CL activity $( \pm \mathrm{SD}, \mathrm{n}=4)$ of $P$. maximus hemocytes reached after stimulation by zymosan particles (base: non stimulated hemocytes; control: hemocytes stimulated without prior contact with bacteria or bacterial extract; A496: hemocytes stimulated after 80 min of contact with 100 bacterial cells of the A496 strain of $V$. pectenicida; $\mathbf{0 . 8 , 4 , 8 , 1 6} \mu \mathbf{L}$ : hemocytes stimulated after 80 min of contact with $0.8,4$, 8 or $16 \mu \mathrm{L}$ of A496 cytoplasmic extract). 


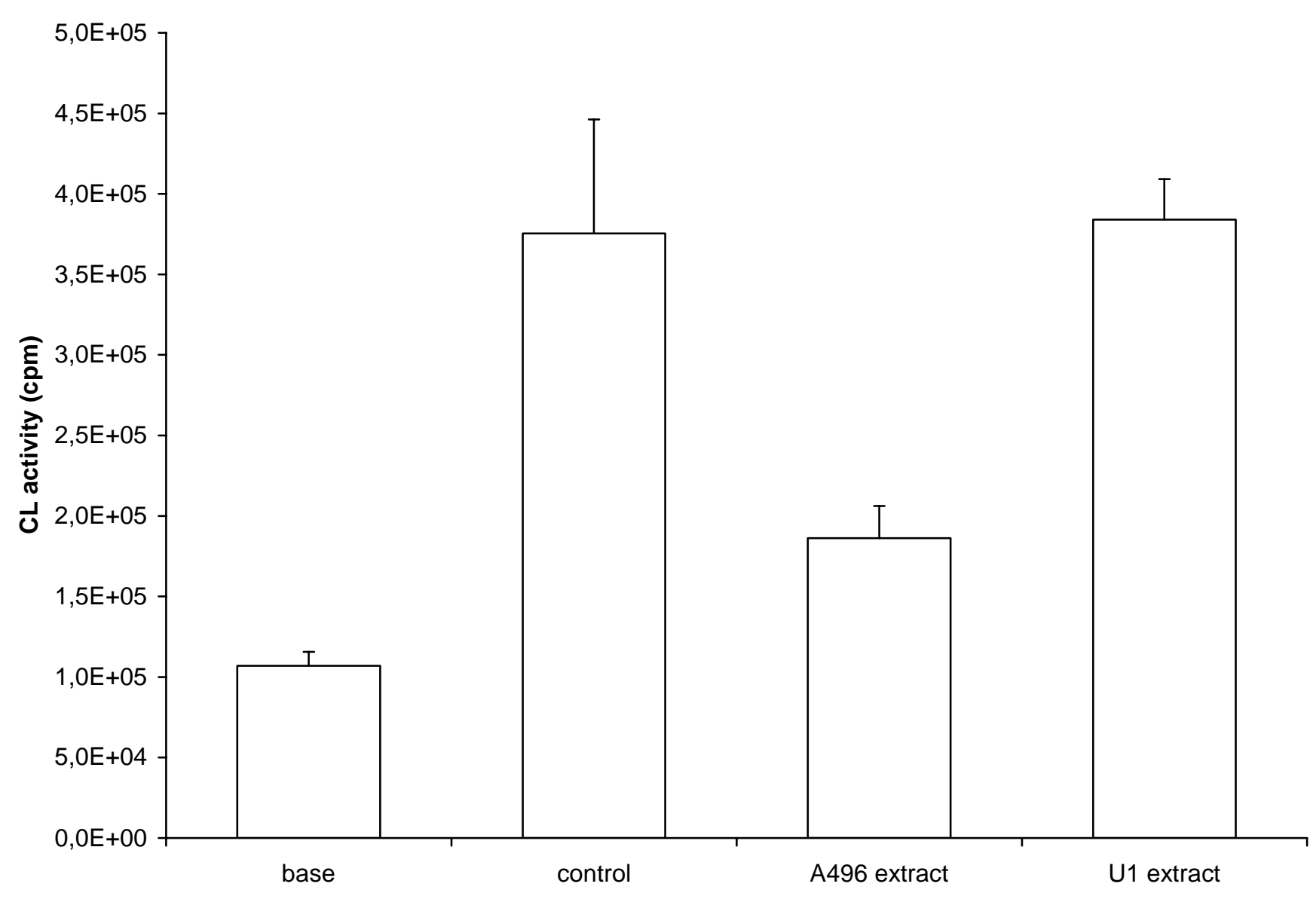

FIG.2 : CL activity ( $\pm \mathrm{SD}, \mathrm{n}=4$ ) of P. maximus hemocytes reached after stimulation by zymosan particles (base: non stimulated hemocytes; control: hemocytes stimulated without prior contact with bacteria or bacterial extract; A496 extract: hemocytes stimulated after 80 min of contact with $25 \mu \mathrm{L}$ of A496 cytoplasmic extract, about $2.4 \times 10^{9}$ bacteria-equivalent. U1 extract: hemocytes stimulated after 80 min of contact with $83 \mu \mathrm{L}$ of $\mathrm{U} 1$ cytoplasmic extract, about $2.4 \times 10^{9}$ bacteria-equivalent). 


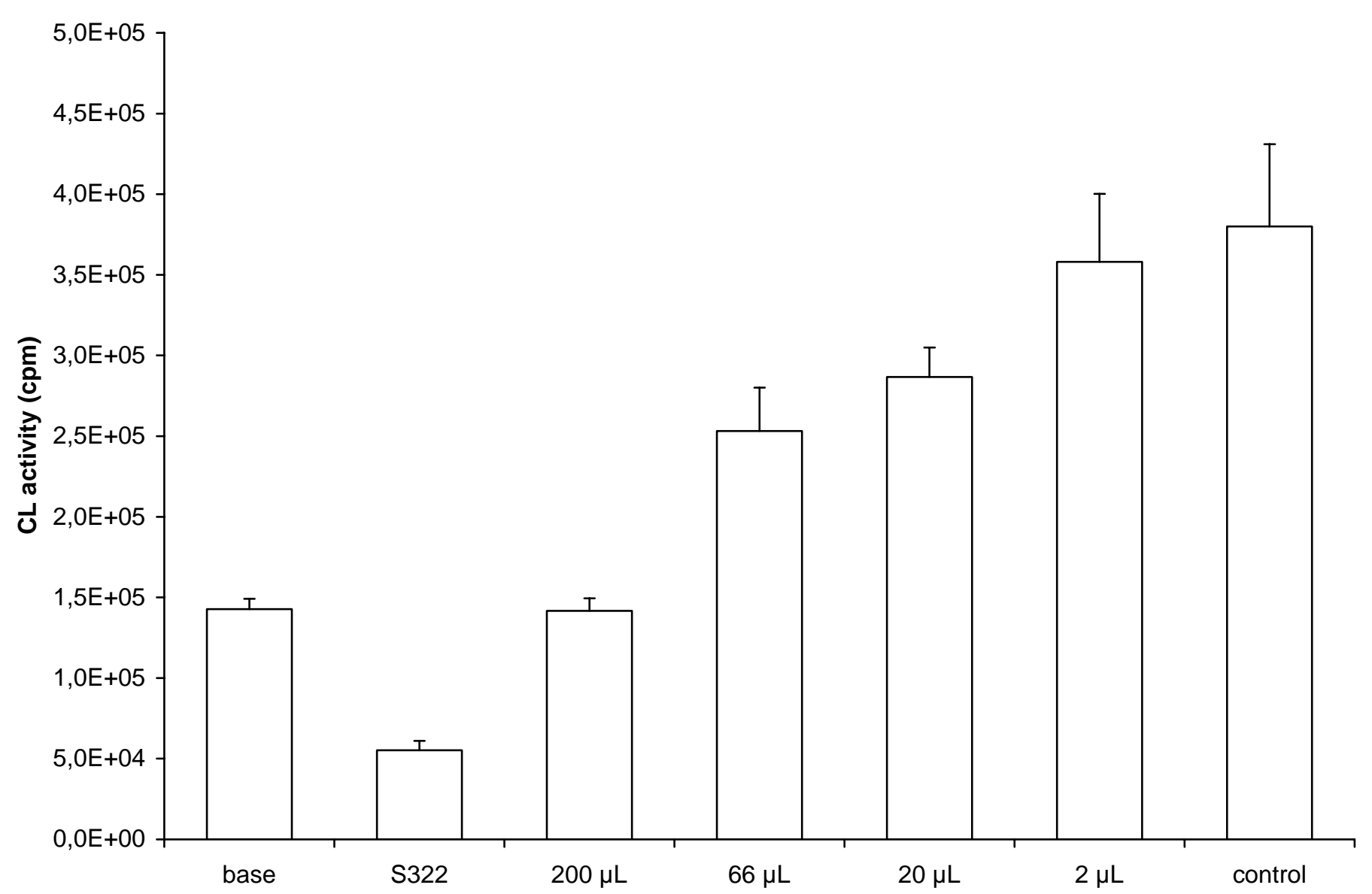

FIG.3 : CL activity ( $\pm \mathrm{SD}, \mathrm{n}=4$ ) of $C$. gigas hemocytes reached after stimulation by zymosan particles (base: non stimulated hemocytes; control: hemocytes stimulated without prior contact with bacteria or bacterial extract; S322: hemocytes stimulated after 80 min of contact with 100 bacterial cells of Vibrio sp. strain S322; 200, 66, 20, $2 \mu \mathbf{L}$ : hemocytes stimulated after 80 min of contact with $200,66,20$ or $2 \mu \mathrm{L}$ of S322 cytoplasmic extract). 


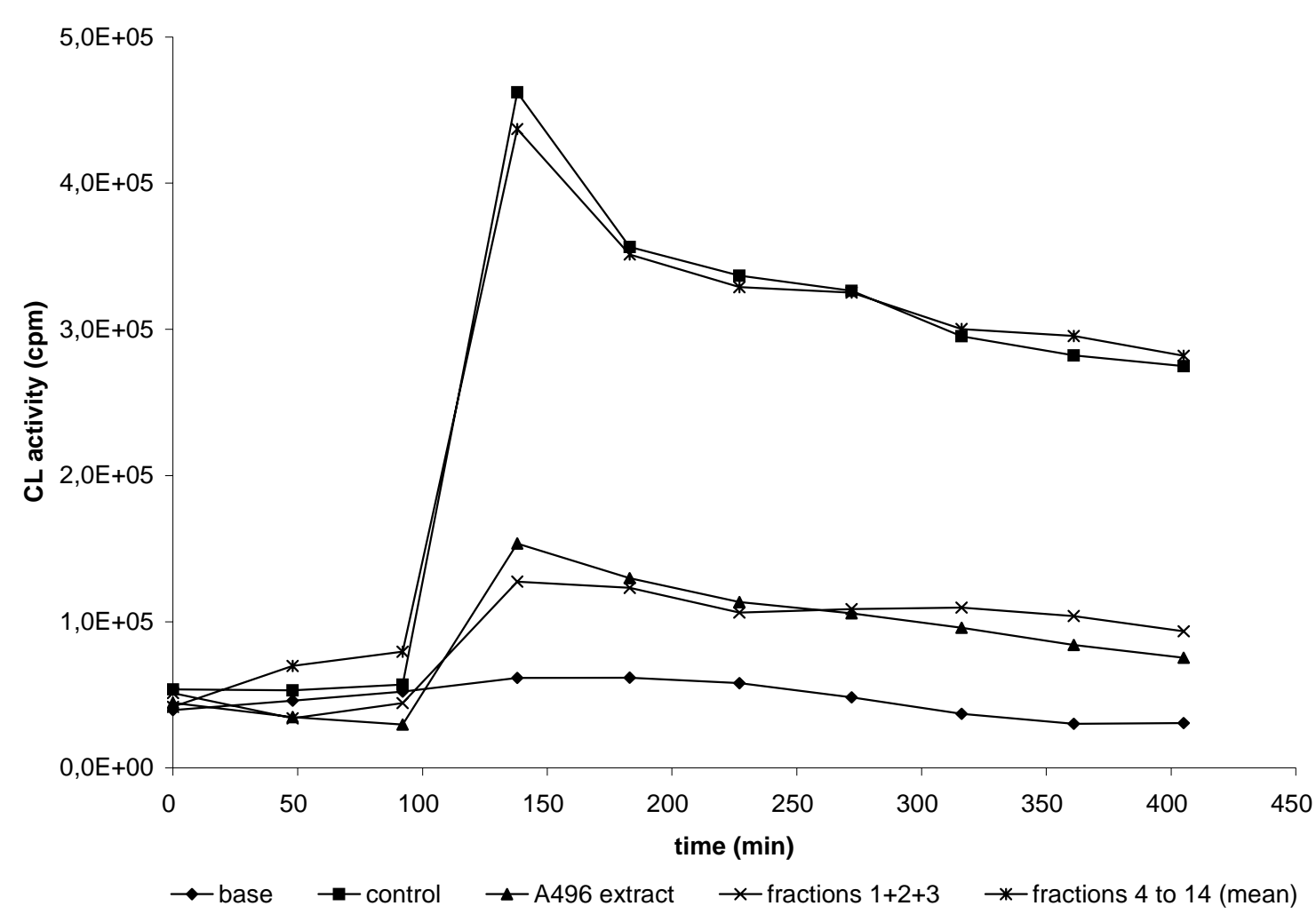

FIG.4 : Variation in CL activity (cpm) of P. maximus hemocytes, non stimulated (base), stimulated by zymosan particles (at $\mathrm{t}=92$ min) without prior contact with bacterial extract (control), or stimulated by zymosan particles after prior contact with fractions of A496 cytoplasmic extract, TCA treated, 1 kDa filtered, eluted on HPLC with a C18 (Hypersil) reverse phase column with methanol gradient $5 / 50 \%$ : fraction 1+2+3 : combined fractions corresponding to the first elution peak ; fraction $\mathbf{n}^{\circ} \mathbf{4}$ to 14 : mean of the results obtained using fractions 4 to 14 tested one by one. Statistical analysis (ANOVA, $n=4, \alpha=0.05$ ) on means at the peak level ( $t=138$ min) showed no significant differences between « fractions 4 to 14 » (calculated individually) and « control » as well as no significant differences between « A496 extract » and « fraction 1+2+3 ». 


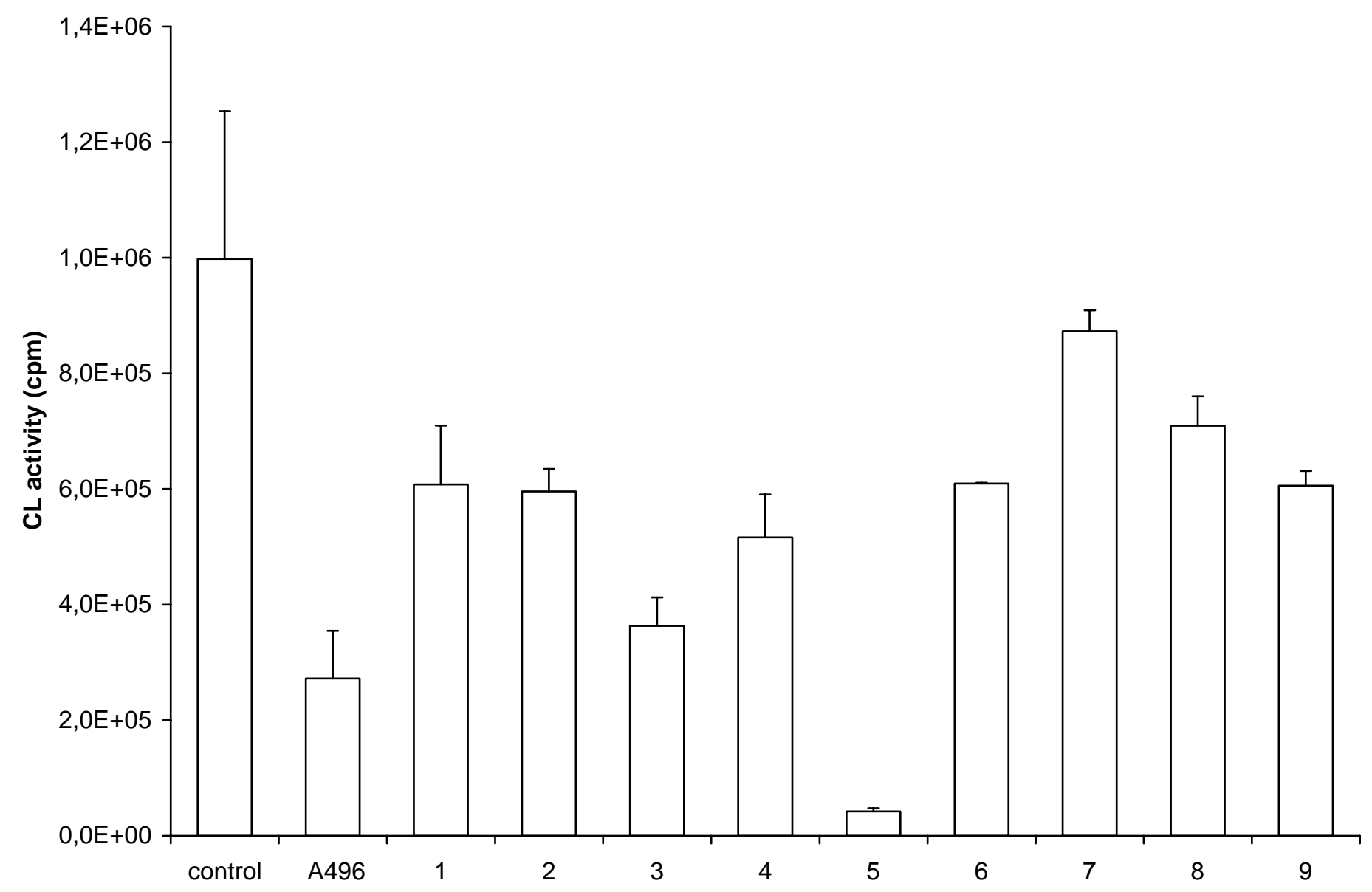

FIG.5 : CL activity ( $\pm \mathrm{SD}, \mathrm{n}=4$ ) of $P$. maximus hemocytes reached after stimulation by zymosan particles : control: hemocytes stimulated without prior contact with bacterial extract; A496: hemocytes stimulated after 80 min of contact with $25 \mu \mathrm{L}$ of A496 cytoplasmic extract ; 1 to 9: hemocytes stimulated after $80 \mathrm{~min}$ of contact with one of the nine fractions of A496 cytoplasmic extract TCA treated, $1 \mathrm{kDa}$ filtered and eluted using water on HPLC with a C18 (Chromasil) reverse phase column. 